\title{
A CATALOG OF SOUTHERN CALIFORNIA EARTHQUAKES, AND ASSOCIATED ELECTRONIC DATA PROCESSING PROGRAMS
}

\author{
By John M. Nordquist
}

\begin{abstract}
Epicenters, origin times, and other pertinent data on approximately 9000 earthquakes in the Southern California region, determined by the Seismological Laboratory at Pasadena for the period from January 1, 1934 to May 17, 1963, have been entered on IBM punched cards. This card catalog may be used as input for programs run on the IBM 7090, and has been converted to punched tape for input to the Bendix G-15D in use at the Laboratory. Programs now operational on the G-15D will produce from the catalog lists of earthquakes which satisfy given criteria of geographical location and/or magnitude range.

A system of G-15D programs for calculating from the catalog the distribution of seismicity over the region is described.
\end{abstract}

\section{INTRODUCTION}

Increasing availability of electronic data processing offers the possibility of wider use of data on local earthquakes in statistical studies. In preparation for such use, the data on approximately 9000 earthquakes located in the Southern California region in the period beginning January 1, 1934 have been recorded on IBM punch cards to serve as input to IBM computers, such as the 7090. Because of slow input of these cards to the Bendix G-15D through equipment installed at the Seismological Laboratory, the data has been transferred to punched paper tape, thus increasing the reading speed by a factor of twenty. This report describes the catalogs and the programs now operational on the G-15D for processing the data they contain.

\section{Region Covered}

Earthquakes listed in the catalog are limited, with a few exceptions, to those occurring in the region mapped in figure 1. Complete listing of all shocks of magnitude 3 and over has been undertaken only for the Southern California statistical area, situated within the shaded boundary in figure 1 .

\section{Catalog Sources}

Data tabulated in the catalog are drawn chiefly from the Bulletin of Local Earthquakes, published by the Seismological Laboratory, supplemented by the results of special investigations on important earthquake sequences in the region. These include: Terwilliger Valley (Wood, 1937), Whittier (Richter, 1941), Walker Pass (Chakrabarty-Richter, 1949), Manix (Richter-Nordquist, 1951), Kern County (Richter, 1955), Desert Hot Springs (Richter et al. 1958), Owens Valley (Richter, 1960, and Walnut (Richter-Gardner, 1960).

The data in the catalog are not homogeneous in quality. Magnitudes for shocks before January 1, 1944 were reported to the nearest half unit. Origin times for shocks before August 1, 1939, and for small shocks in certain aftershock sequences at later dates, are reported to the nearest minute. No provision has been made in 


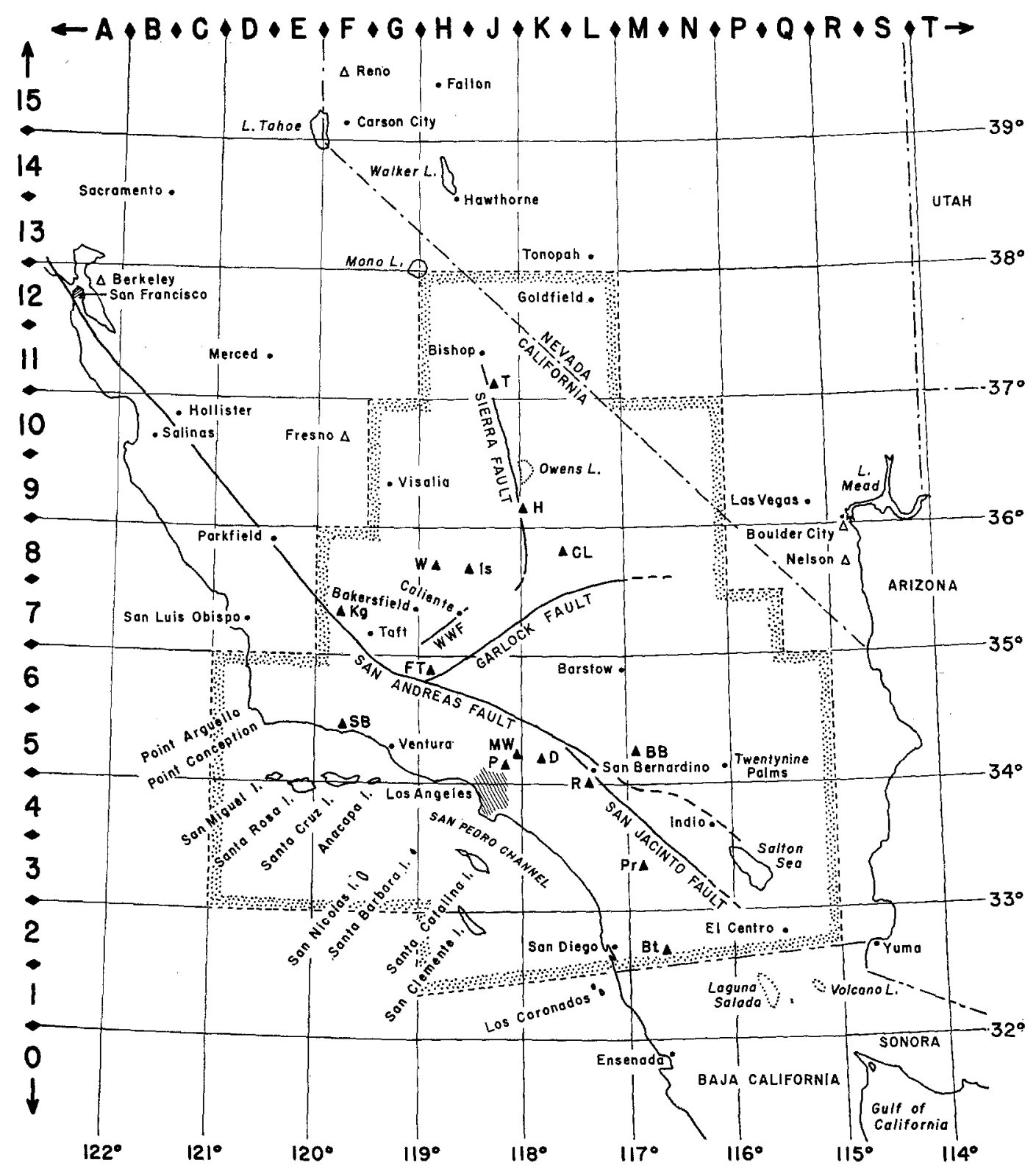

FIG. 1. Index map showing boundary of southern California statistical region (stippled) and stations of C.I.T. network on Jan. 31, 1955.

the catalog to differentiate these magnitudes and origin times from those reported to the nearest tenth unit or the nearest second, respectively.

Epicenters for earthquakes outside the Southern California statistical area may be approximate values obtained from the readings of the Pasadena network, or tentative epicenters determined by the USCGS. Within the statistical area, coverage and accuracy of location have increased generally with the increase in record- 
ing stations (eight: 1939-1949, twelve: 1949-1952, fifteen: 1952-1956, eighteen: 1956-1957, and nineteen since 1957) and with improvement in recording and timing systems. Temporary operation of auxiliary stations in the epicentral areas of large shocks (Walker Pass, 1946; Desert Hot Springs, 1948-49; Kern County, 1952; and Baja California, 1956) has aided in location of aftershocks, and in instances has furnished a basis for better location of the principal shock of the series by comparison of its arrival times at permanent stations with the arrival times of a well-located aftershock. There are still periods during which a station is not operating properly, with a resultant loss of data critical for the location of earthquakes occurring in the vicinity.

In addition, the location process itself has varied. Almost all earthquakes prior to June 17, 1961, were located by graphical methods based on standard travel time curves compiled and twice revised by Gutenberg $(1932,1944,1951 \mathrm{c})$ for foci at a fixed depth, making occasional allowance for possible shallower focal depth by comparison with observed travel times from large quarry blasts (Wood and Richter, 1931, 1933, Gutenberg, 1951a, 1951a) or for variations in regional structure and faulting mechanism, (Gutenberg, 1943a, 1943b, Gutenberg and Richter, 1943). A few exceptionally well recorded earthquakes were subjected to a leastsquare solution for epicenter and origin time, assuming standard depth of focus.

With the completion by Nordquist (1962) of a program for the G-15D, it became possible to undertake routine least-square solutions for all well-recorded earthquakes in the region, to determine origin time, epicenter, and focal depth on the basis of a plane-parallel structure with constant velocities in two layers over a half-space. Solutions have been made using the structure corresponding to Gutenberg's 1951 travel times, and with a structure found by Press (1960). An expanded locations program by Gardner, operating on the IBM 7090, can compute on the basis of these structures, or of one with non-parallel plane boundaries, or of a general structure defined by the depths of three discontinuities and the velocities immediately above and below each at lattice points spaced $40 \mathrm{~km}$ apart in $X$ and $Y$ on a plane tangent to the spheroid at $35^{\circ} \mathrm{N}, 118^{\circ} \mathrm{W}$. The latter structure is a first approximation to the structure of the region indicated by Pakiser (1963), Pakiser and Hill (1963), Healy (1963), Eaton (1963), and Roller and Healy (1963). Earthquakes from June 17, 1961 to May 17, 1963 have been located where possible by these computer programs, using the plane-parallel structure. Convergence on iteration of the least-square procedure with rejection of data giving large time residuals occurs in roughly 75 per cent of the solutions attempted. In general, the remainder converge fairly well for the epicenter, but fail to reach a satisfactory solution for depth and origin time. These failures occur for earthquakes near the lower margin of 3.0 in magnitude and those located near or outside the periphery of the station network, or too distant from any station to record at least one direct $P$ phase. In such cases, it has been the practice to accept the computed epicenter, obtain an origin time based on a standard focal depth and the arrival times of $P$ at whatever stations appear to be most reliable under the circumstances, and assign a low value to the quality of location.

In the process of checking out the locations programs on the computers, several well-recorded shocks have been located by the different programs, on the basis of 
several different sturctures. On the whole, the differences in epicenter and origin time encountered have been within the expected limits of accuracy of location set by the possible errors and uncertainties in identifying the phases used and determining their arrival times.

The supposed accuracy of each location is indicated by a quality designator, as follows:

$A$. exceptionally accurate

$B$. epicenter within $5 \mathrm{~km}$., origin time to nearest second

C. epicenter within $15 \mathrm{~km}$., origin time to a few seconds

$D$. very rough.

A gradual change in the inclusion of small shocks is indicated by the following quotations from descriptive material accompanying the Local Bulletin:

Jan., 1932 "A great many of the shocks reported are comparatively small."

Aug., 1937 "Shocks of magnitude less than 2.5 are not reported unless the location is of quality $A$ or $B$."

Feb., 1944 "Small shocks (magnitude 3 or less) are usually not included unless reported felt."

Jan., 1953 "In general, this includes those of magnitude 3.0 and over. Smaller shocks are listed when there is a report of their having been felt, or when circumstances are favorable for location, or when there is some special point of interest. Special care has been taken to make cataloguing complete for shocks of magnitude 3.0 and over in Kern County".

Oct., 1954 "As previously, special effort has been made to catalogue all shocks of magnitude 3.0 and over within the area of Southern California covered by our stations."

Jan., 1958 "Artificial earthquakes due to explosions, etc., are not listed."

In the earlier years, some large quarry blasts near Pasadena, Riverside, and Victorville were located and reported as earthquakes. Care has been taken to eliminate those which were later definitely determined to be blasts, but there is a possibility that some remain in the card catalog.

\section{Catalogue Formats}

Figure 2 shows the format of the IBM card catalog entry for each earthquake. On punch tape, the data are stored as five words of seven characters each. To make this possible, the map code, the standard errors, and the literal qualifier in the source code are omitted and a minimum amount of compression is done on the binary-coded decimal data. The month is converted from decimal to hexadecimal: $u, v$, and $w$ replacing 10,11 , and 12 . The quality is transformed from a letter to a digit, 1, 2, 3 and 4 replacing $A, B, C$ and $D$.

\section{SelECTIVE Listing}

Two programs are available for selecting from the catalog a list of the earthquakes with epicenters in limited regions. One produces a typed list of shocks occurring within any specified distance of a point whose latitude and longitude are given, together with the distance of each from that point. The second produces a 


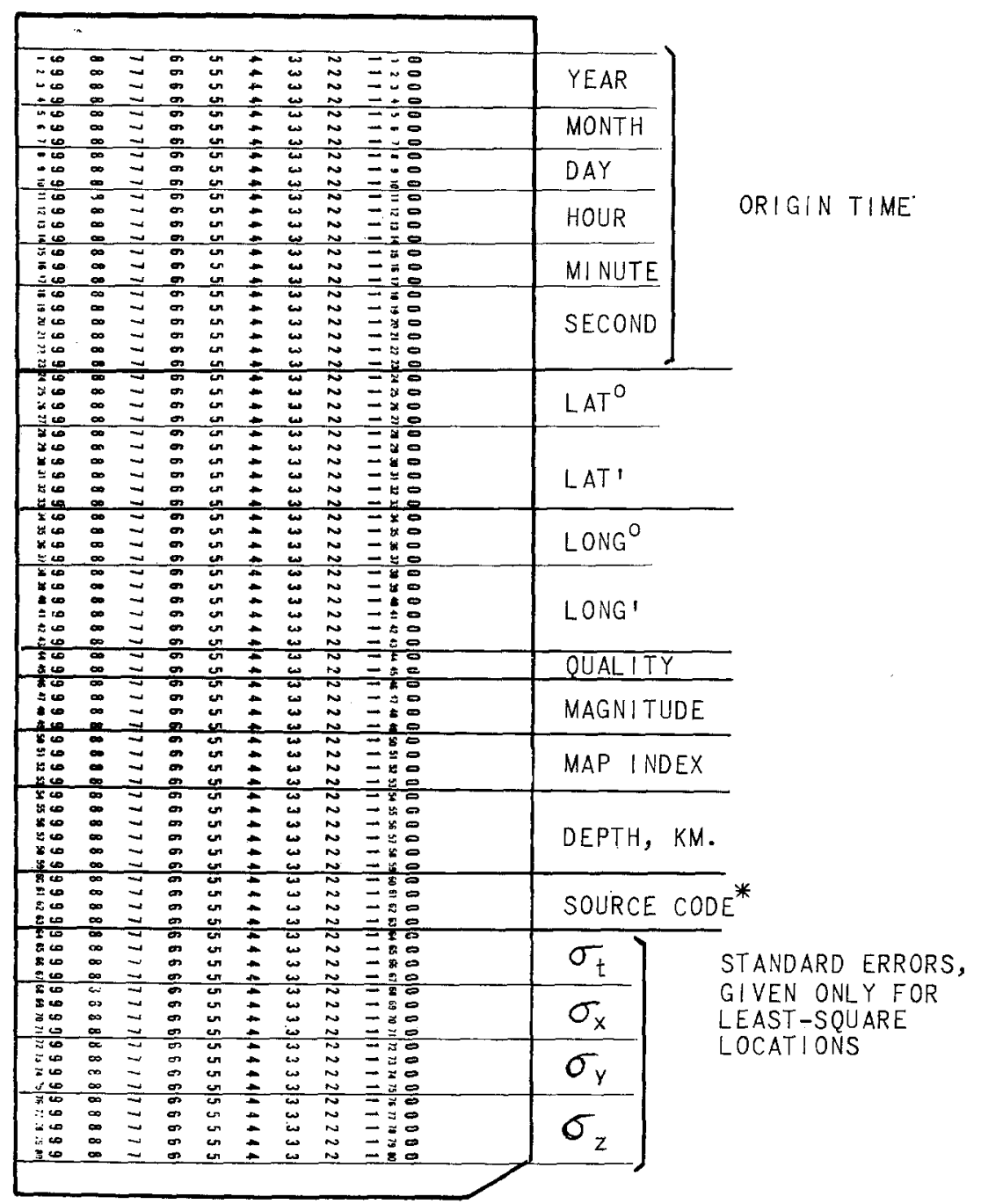

* IA, 1B, IC: least-square solution, obtained on Bendix, Fortran II, or Fortran IV, respectively; 6: Berkeley Station;

7: USCGS; 8: Pasadena, hand solution; 9: Allen-St. Amand catalog.

FIG. 2. Format of IBM earthquake catalog card.

punched tape list of those earthquakes: (a) whose epicenters lie within a quadrangle specified by limiting latitudes and longitudes, (b) whose magnitudes are equal to or greater than any chosen value, or (c) that satisfy both (a) and (b). The tape list produced by this program can be used as input to the G-15 as data for computation, or for typing in standard format.

\section{Derived Catalogues}

In addition to the complete chronological list of earthquakes, there exist two other punch tape versions. One contains a chronological list for each degree of lat- 


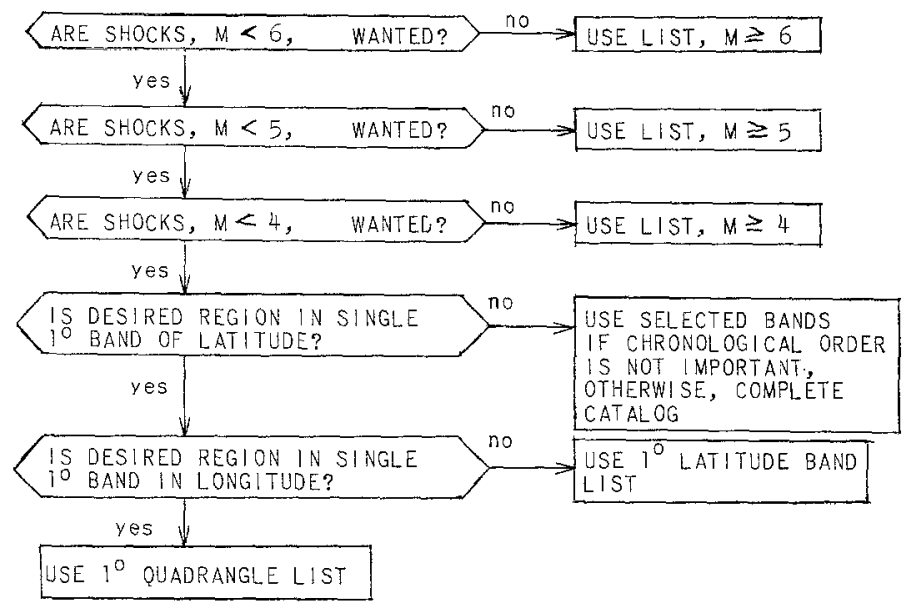

FIG. 3. Flow chart for choice of earthquake catalog version most economical of computer time.

$9 \quad 83 \quad s \quad 35.0 . .118 .5$

$\begin{array}{rrrrrr}.000 & 4.688 & 25.375 & 54.000 & 12.188 & 6.188 \\ 412.938 & 661.875 & 93.938 & 101.375 & 1416.000 & 238.500 \\ 17.750 & 4.625 & 2.500 & 26.938 & 130.750 & 1404.813 \\ 3.500 & 3.188 & 305.313 & 29.250 & 268.938 & 167.125 \\ 55.688 & 16.938 & 279.750 & 90.750 & 127.500 & 82.563 \\ 143.500 & 378.125 & 33.813 & 60.188 & 9.000 & 13.063\end{array}$

35.0 .118 .0

$\begin{array}{rrrrrr}26.188 & 9.313 & .813 & .750 & .000 & .625 \\ 54.313 & .625 & .000 & 1.750 & .000 & .000 \\ 78.750 & .313 & 1.063 & .000 & .000 & .000 \\ 46.563 & 5.125 & .000 & .438 & 3.625 & 1.000 \\ 28.875 & 8.375 & 1.500 & .438 & .000 & .000 \\ 4.750 & 2.938 & 1.500 & .000 & .000 & 35.875\end{array}$

Fig. 4. Sample of output from seismic strain release computation, showing in geographic order the strain release, 1934-1962, for each five-minute cell from $35^{\circ}$ to $35^{\circ} 30^{\prime} \mathrm{N}, 118^{\circ}$ to $119^{\circ} \mathrm{W}$, in terms of the strain release from one magnitude 3 earthquake. Latitude and longitude preceding each table are those of the southeast corner of the area covered in that table.

itude and the other contains a chronological list for each one-degree quadrangle in the region. These are of value if a study is to be made of all listed earthquakes within a limited area.

The selective listing routine has been used in preparing chronological tape lists of all earthquakes (a) of magnitude 4 and over, (b) of magnitude 5 and over, and (c) of magnitude 6 and over, use of which will greatly reduce required computer time if smaller earthquakes are not to be considered. The flow chart in fig. 3 directs the choice of the best version of the catalog for any particular use.

\section{Application}

The failure of the Baldwin Hills Reservoir in western Los Angeles, Dec. 14, 1963, was accompanied by fracture of the reservoir floor. In view of speculation regarding earthquakes as a causative factor in the failure, the system described here has 
been used to prepare lists of all earthquakes reported with epicenters within 50 $\mathrm{km}$., those of magnitude 5.0 and over within $140 \mathrm{~km}$., and those of magnitude 6.0 and over within $340 \mathrm{~km}$. of the reservoir site.

\section{Measures of SeIsmicity}

St. Amand (1956) proposed as a measure of seismicity of an area the sum of the square roots of the energies of the earthquakes with epicenters in that area, per unit area, and mapped the geographical distribution of this parameter in the aftershocks of the Kern County earthquake of July 21, 1952. Richter, Allen, and Nordquist (1958) mapped this distribution for the aftershocks of the Desert Hot Springs earthquake of December 4, 1948, referring to the measure as strain-release density. Bonelli and Chacón (1961) consider both strain-release density and the number of recorded earthquakes per unit area as possibly valid measures of seismicity. In using the latter measure, counting must be limited to shocks with magnitudes greater than some fixed lower limit above which it is certain that all earthquakes occurring in the region to be compared are included and are located with reasonable accuracy, otherwise comparisons are meaningless. For the Southern California region, this limit is magnitude 3 except during the first few hours of aftershock sequences following major quakes, in which cases the omission of some quakes of magnitude somewhat larger than 3 should not affect the overall picture significantly.

For the present program

$$
\log E^{0.5}=6+0.9 M
$$

has been accepted as the equation connecting magnitude and energy, and the strain release connected with a shock of magnitude 3 has been chosen as unit. This leads to the expression.

$$
\text { strain release }=\sum 10^{0.9(M-3)} \text {. }
$$

\section{Computing Distribution of Seismicity}

In the system of programs for computing the distribution of seismicity, the entire region is divided into cells 5 minutes in longitude by 5 minutes in latitude, and the seismicity of each cell is determined from the catalog. This division permits simple handling of the data in manageable sections, and is thought to be as detailed as the general accuracy of location of epicenters justifies. To minimize input time on the computer, the operation is done in several stages. The first two steps divide the catalog into subsets for each degree of latitude and each of these into subsets for each degree of longitude in the region. The resulting lists for each onedegree quadrangle are processed individually, producing a punch-tape listing of the seismic strain release and of the number of earthquakes of magnitude 3 or over for each five-minute cell in the quadrangle. An output program is used to produce a typed list (fig. 4) of either seismic strain release or number of earthquakes, in geographical order, ready to be transferred to a map for contouring.

A program is provided for smoothing a distribution by computing the weighted 
mean of the cells in each 15-minute quadrangle and inserting it in the center cell. Iteration of this smoothing procedure gives a weighted mean over each 25 -minute quadrangle.

The system does not correct for the difference in the area of the cells due to difference in latitude. This amounts to about 5 per cent from $32^{\circ} \mathrm{N}$ to $36^{\circ} \mathrm{N}$. If this is considered significant, the values typed by the program should be divided by factors proportional to the cosine of the latitude.

\section{ACKNOWLEDGMENTS}

This paper represents research conducted under Grant No. AF-AFOSR-25-63 of the Air Force Technical Applications Center as part of the Advanced Research Projects Agency's Project VELA UNIFORM.

\section{REFERENCES}

Bonelli Rubio, Juan Maria, and Luis Chacón Alonso

1961. Estudio de la Sismicidad de la Zona Murciano-Alicantina Instituto Geografico y Catastral, Madrid, $19 \mathrm{pp}$.

Chakrabarty, S. K. and C. F. Richter

1949. "The Walker Pass Earthquakes and Structure of the Southern Sierra Nevada" Bull. Seism. Soc. Amer., 39: 93-107.

Eaton, Jerry P.

1963. "Crustal structure from San Francisco, California, to Eureka, Nevada, from seismicrefraction measurements" Jour. Geoph. Res., 68: 5789-5806.

Gutenberg, B.

1932. "Travel-time curves at small distances and wave velocities in Southern California" Gerl. Beitr. z. Geoph., 35: 6-50.

1943a. "Seismological evidence for roots of mountains" Bull. Geol. Soc. Amer., 54:473-498.

1943b. "Earthquakes and structure in southern California" Bull. Geol. Soc., 54:499-526.

1944a. "Travel times of principal $\mathrm{P}$ and $\mathrm{S}$ phases over small distances in Southern California." Bull. Seism. Soc. Amer., 34: 13-32.

1944b. "Reflected and minor phases in records of near-by earthquakes in southern California" Bull. Seism. Soc. Amer., 34: 137-160.

1951a. "Travel times from blasts in southern California" Bull. Seism. Soc. Amer., 41: 5-12.

1951b. "Waves from blasts recorded in southern California" Trans. Amer. Geoph. Union, $33: 427-431$.

1951c. "Revised travel times in southern California" Bull. Seism. Soc. Amer., 41: 142-163.

Gutenberg, B. and C. F. Riehter

1943. "Apparent origin time of $\overline{\mathrm{S}} "$ Bull. Seism. Soc. Amer., 33: 269-279.

Healy, J. H.

1963. "Crustal structure along the coast of California from seismic-retraction measurements" Jour. Geoph. Res., 68: 5777-5787.

Nordquist, J. M.

1962. "A special-purpose program for earthquake location with an electronic computer" Bull. Seism. Soc. Amer., 52: 431-437.

Pakiser, L. C.

1963. "Structure of the crust and upper mantle in the western United States" Jour. Geoph. Res., 68: 5747-5756.

Pakiser, L. C. and D. P. Hill

1963. "Crustal structure in Nevada and southern Idaho from nuclear explosions" Jour. Geoph. Res., 68: 5757-5766.

Press, Frank

1960. "Crustal strueture in the California-Nevada region" Jour. Geoph. Res., 65: 1039-1051. 
Richter, C. F.

1942. "Earthquake near Whittier, California, Jan. 29, 1941" Bull. Seism. Soc. Amer, 32: $7-9$.

1950. "Velocities of P at short distances" Bull. Seism. Soc. Amer., 40: 281-289.

1955. "Foreshocks and Aftershocks", in Earthquakes in Kern County, California during 1952 Division of Mines, Bull. 171, pp. 177-197.

1960. "Earthquakes in Owens Valley, California, January-February, 1959" Bull. Seism. Soc. Amer., 50: 187-196.

Richter, Charles F. and John M. Nordquist

1951. "Instrumental Study of the Manix Earthquakes" Bull. Seism. Soc. Amer., 41: 347-388.

Richter, Charles F., Clarence R. Allen and John M. Nordquist

1958. "The Desert Hot Springs Earthquakes and their Teetonic Environment" Bull. Seism. Soc. Amier., 48: 315-337.

Richter, Charles F. and John K. Gardner

1960. "The Walnut, California Earthquakes of July-August, 1959" Bull. Seism. Soc. Amer., 50: $181-185$.

Roller, John C. and John H. Healy

1963. "Seismic-refraction measurements of crustal structure between Santa Monica Bay and Lake Mead" Jour. Geoph. Res., 68: 5837-5849.

St. Amand, Pierre

1956. "Two Proposed Measures of Seismicity" Bull. Seism. Soc. Amer., 46: 41-45.

Wood, H. O.

1937. "The Terwilliger Valley Earthquake of March 25, 1937' Bull. Seism. Soc. Amer., 27: 305-312.

Wood, H. O. and C. F. Richter

1931. "A study of blasting recorded in southern California" Bull. Seism. Soc. Amer., 21: $28-46$.

1933. "A second study of blasting recorded in southern California" Bull. Seism. Soc. Amer., 23: $95-110$.

\section{SEISMOLOGICAL Laboratory}

California Instivute of Technology

Pasadena, California

(Division of the Geological Seiences, Contribution No. 1234)

Manuscript received January 25, 1964. 